\title{
Neonatal records and the computer
}

\author{
COLIN H. M. WALKER*
}

SUMMARY To use a combined single document clinical case sheet/computer record which can form the basic document for a life medical record is a practical proposition. With adequate briefing doctors and nurses soon become familiar with the record and appreciate its value. Secretarial and clerical requirements are reduced to a minimum as transcription of medical data is eliminated, so greatly speeding up processing and feed back to the medical services. A few illustrations of trends in neonatal statistics and of computer linked maternal/neonatal data are presented.

For too long newborn babies have not been regarded nor recorded as patients in their own right and much information, valuable to the furthering of neonatology, is still being lost. It seemed appropriate therefore to construct a new record/computer system which would meet the needs of the clinician, act as a complementary document to the Scottish Maternity Record (SMR 2), and assess the value of a computer operation. In 1970 a small group* was selected from among 30 interested Scottish paediatricians to begin work on what has now become established as the Scottish Medical Record (Newborn) or SMR 11, and the initial experience has already been reported in brief (Cockburn, 1974). The purpose of this paper is to summarize and offer to others the benefit of the experience gained in the years of planning and operation of this program. Thus we hope to encourage those who are designing programs of their own, of whom there seem to be a large number, to consider making them, if not similar, at least compatible with this one.

\section{Objectives}

The working group consisted of doctors from all parts of Scotland in widely different types of paediatric practice. The limited knowledge of computer programs on which they were to base their objectives was ably amplified by Mr. Harvey Scott, the computer manager, Tayside Health

Received 13 September 1976

*Convener, Working Group on the Scottish Medical Record (Newborn); F. Cockburn, Vice-convener, Edinburgh; N. A. Coutts, Paisley; B. M. Dawson, Aberdeen; W. Doig, Glasgow; C. A. S. Galloway, Inverness; M. M. Kerr, Glasgow; M. J. Patrick, Glasgow; G. Stark, Bangour; Dr. J. A. Clarke (previously Dr. J. D. Donnelly), Information Services Division, Common Services Agency, Scotland (formerly, Research and Intelligence Unit, SHHD).
Board, and by Dr. M. A. Heasman and staff of the department known then as the Research and Intelligence Unit, Scottish Home and Health Department (SHHD). The group considered the primary objectives to be:

(1) Recognition of the baby as a separate entity from mother at birth and initiation of a confidential life record to which further medical information could be added at any time. (2) The prospective capture of accurate, standardized neonatal clinical data, and provision of annual statistics on all babies born in Scottish hospitals. (3) Recording on the same document of noncoded information required for clinical care and coded data (for storage in the computer file) of information not available through linkage with the maternal file. (4) Storage of such data for analysis and rapid retrieval by the computer.

The secondary objectives which related more to the actual operation of the system included:

(1) Limitation of the work required of medical and clerical staff by designing a combined clinical bedside record/computer code sheet. This would eliminate two potential sources of error by (a) eliminating the need to transcribe data from clinical to computer documents (a requirement of most other systems and one for which extra secretarial staff are essential), and (b) eliminating the need for the interpretation of clinical information by nonclinical personnel. (2) Provision of 'instant copy' so as to ensure the availability of the clinical record at all times for patient care and yet allow rapid transfer of copy to the computer service. (3) Construction of the record so that it could be easily photocopied for storage in the mother's notes, or for sending to the general practitioner or Community Child Health Service without, except when specially indicated, further correspondence. (4) Design of a form which provided 
for the optimum entry of clinical information, i.e. a memory check list requiring minimal writing by medical staff and enough space for free-hand narrative. (5) Provision of computer space for items of individual interest to the participants (local option).

\section{The document}

The 1976 record (Fig. 1) produced on NCR paper (a carbon copy assembly having been tried and discarded) is the result of experience gained over more than 4 years during which the layout has been redesigned 8 times with three different printings. Currently, in the West of Scotland and in Stornoway, an abbreviated form of the SMR 11 is in use (Fig. 2). The coded data of this one are compatible with the computer program for the full document so the two forms are identically processed. A further modification will be made for 1977 and subsequent years to include additional data on certain newborn babies currently required by the Information Services Division, Common Services Agency for the Scottish Health Service.

The data coded are obviously basic, and further case notes are necessary when the infant requires special care. Rather than constructing individual codes for the numerous items of 'special care' diagnosis and treatment, the suitability of a 'diagnostic' section of moderate size to note such events is being assessed.

The document can be initiated in the antenatal clinic, e.g. on 'booking' or in the labour ward at the time of delivery, according to local choice. Thus the noncoded obstetric information required by the paediatrician at the cotside is provided and recall of this data is achieved through computer linkage with the maternal record-SMR 2 (Fig. 3).

Entries and diagnostic decisions can be recorded on the SMR 11 at the cotside. On discharge only a check for completion of the record is required, for the computer will reject an incomplete record. Some medical or secretarial time is required at this point, but no further medical decisions or transcription of data are needed. Having used fairly standard nomenclature a doctor or secretary can easily select the diagnostic code number from the Perinatal Supplement (described below). The completed top copy can be photocopied as often as local arrangements require before transfer to the computer centre for processing. The undercopy is retained in the baby's record.

Perinatal supplement of the Cardiff Diagnostic Classification

Paediatricians throughout the UK have been encouraged to use the Cardiff Diagnostic Classifi- cation as it provided for children a more detailed code than the International Classification of Diseases (ICD). It was compiled in Cardiff in 1962, revised in 1969 by the Nomenclature Committee of the British Paediatric Association (BPA), and is in fairly widespread use. Work has begun on a further revision in preparation for the publication of the 9th revision of the ICD and the two will be entirely compatible. Also in 1962 a small Neonatal Supplement was published, but it was agreed by the Scottish Working group and by the BPA that this too was due for revision.

This was undertaken by Dr. M. J. Patrick, Stobhill General Hospital, Glasgow, with the author and with the invaluable assistance of two members of the aforementioned committee, Prof. A. G. Watkins and Mr. J. Morgan (then Records Officer), both of Cardiff. The original Neonatal Supplement has been extended to form a Perinatal Code numerically compatible with the present ICD and rewritten in the style expected in the 9th revision of the ICD to be published in a few years. This is now produced in temporary form by the Information Services Division of the CSA in Scotland and is the diagnostic code used for completion of all SMR 11 records.

\section{Processing procedure}

Records are sent to the computer centre in batches (usually monthly) and on receipt the data are keyed on to magnetic discs-twice for accuracybefore being fed into the computer for a validity check. Most items have had numerical limits set, e.g. gestation 20-45 weeks; occipitofrontal head circumference 10-49.9 cm, and entries outside such limits will effect rejection of the record. All records are returned to source together with a print-out of a list of all the accepted records. The rejected records are corrected by the staff at the place of origin and resubmitted for processing. The full list of accepted records can be checked against the labour ward log to ensure that data of all babies born in that institution have indeed been added to the SMR 11 master computer file.

The computer program is written in one of two languages-COBOL or PLAN. A prearranged print-out is sent to all participants, currently containing all basic information, full details of all deaths, and a limited number of tables showing correlations of clinical data with longitudinal and horizontal percentages. This basic print-out is being modified in the light of experience, and ad hoc requests either for national or individual hospital use can be added. In the Tayside area a link with the maternal records has been established 


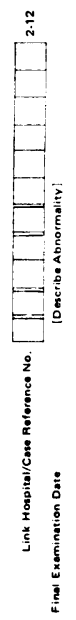

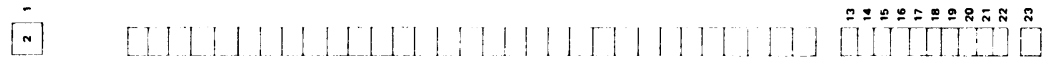

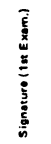

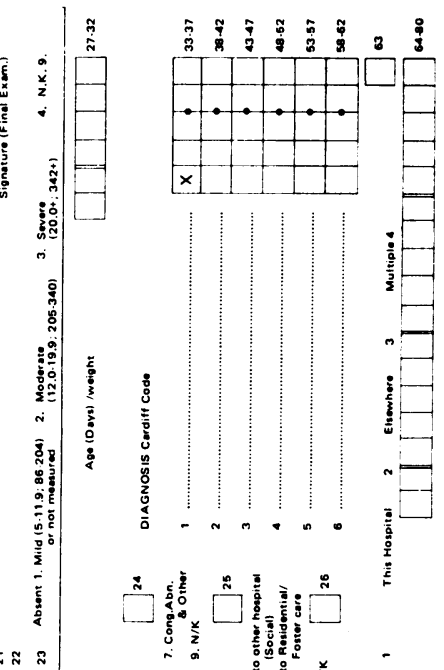

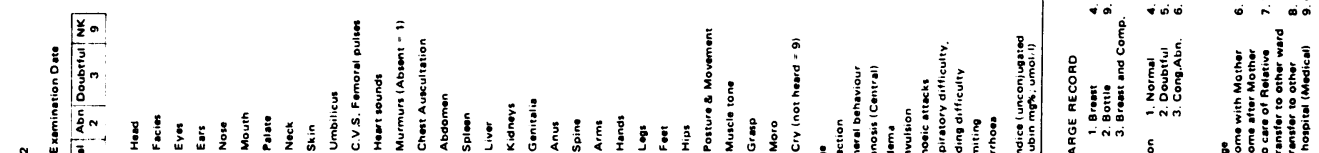

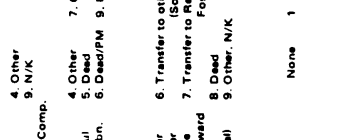

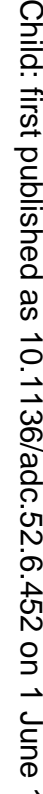

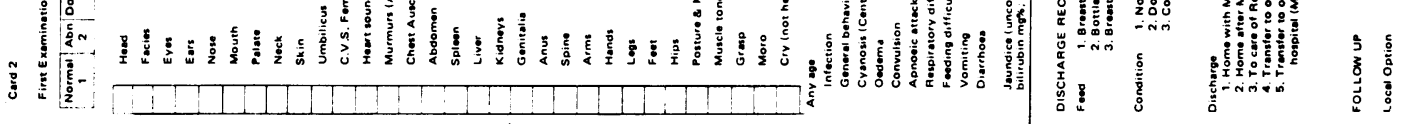

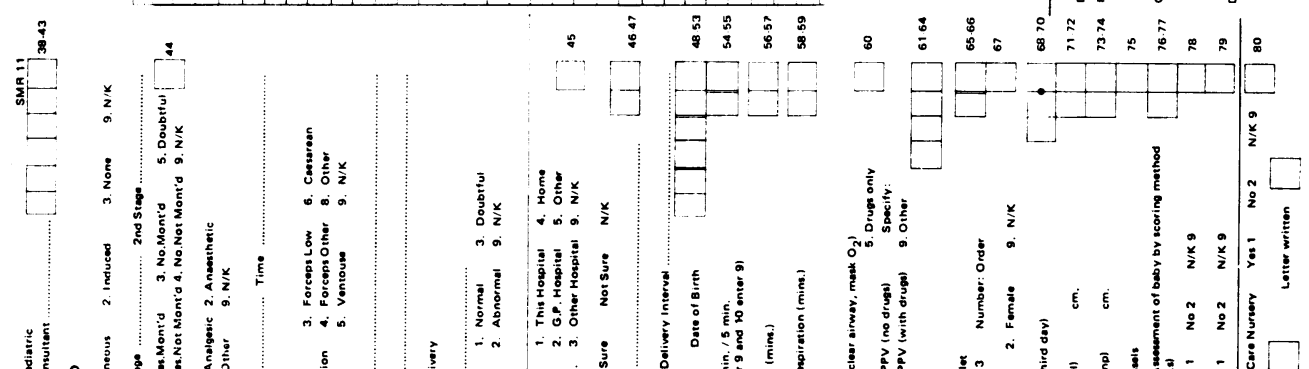

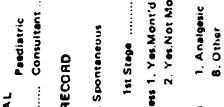

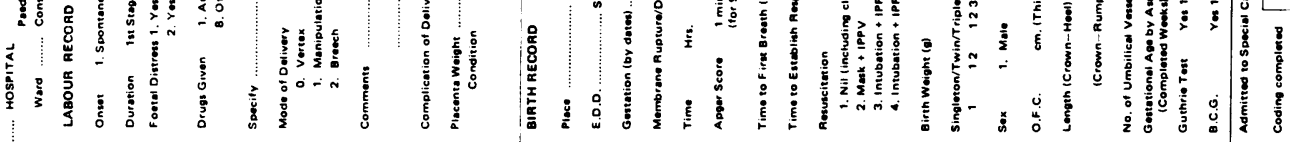

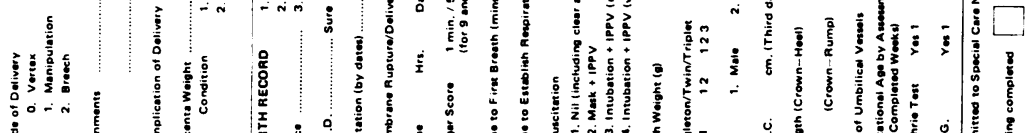

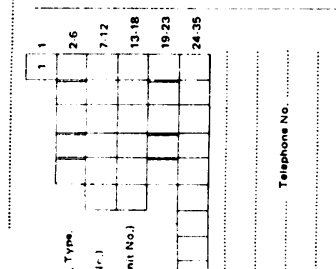

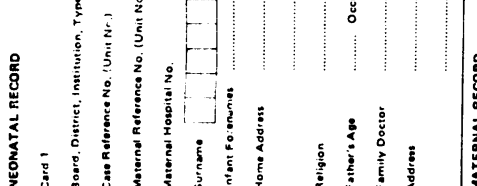
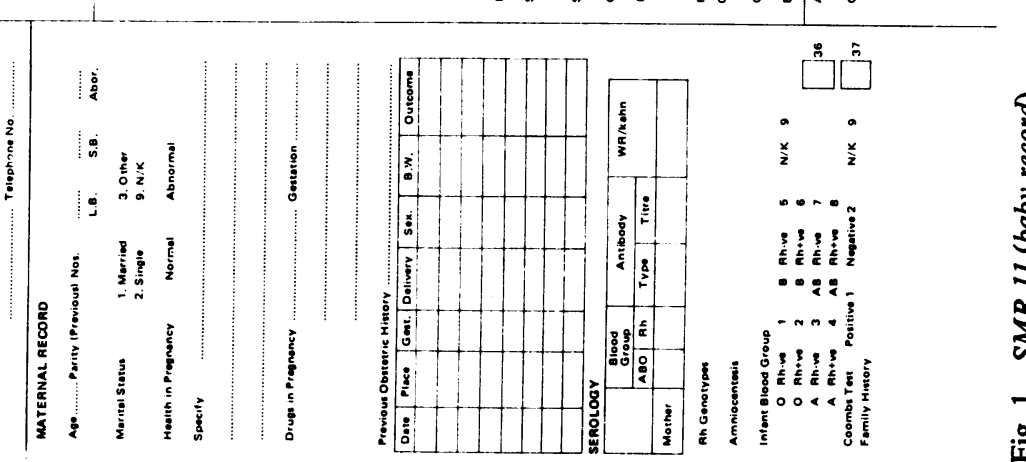
Cord 1

Board, District, Institution, Type

Case Reference No. (Unit No.)

Maternal Reference No. (Unit No.)

Maternal Hospital No.

Surname

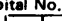

Infant Forenames

Home Address

... Telephone No.

Ward ............. $\begin{aligned} & \text { Paodiatric } \\ & \text { Consultant }\end{aligned}$

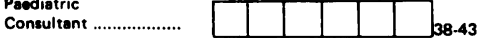

BIATH RECORD

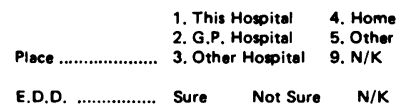

Gestation (By Dates)

(1)

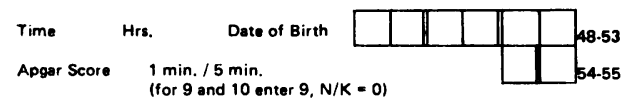

Pesuscitation

1. Nil (including clearing airway)

2. Mask + IPPV

3. Intubation + IPPV (no drugs)

4. Intubution + IPPV (with drugs)

Birth Woight

Single / Twin / Triplet Number

Order

Sex 1. Male 2. Female 9. N/K

Admitred to Soecial Care Nursery 1. Yes

Drugs only Spocify

9. Other

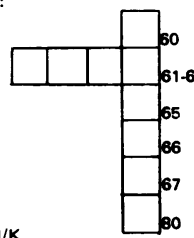

Card 2

Board, District, Institution, Type

Case Reference No.

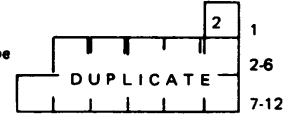

DISCHARGE RECORD

Condition 1. Normal 4. Other 7. Cong. Abn $\begin{array}{lll}\text { 2. Doubtful } & \text { 5. Dead } & \text { \& Other } \\ \text { 3. Cong. Abn. } & \text { 6. Dead/PM } & \text { 9. N/K }\end{array}$

Discharge

$$
\begin{aligned}
& \text { 1. Home with Mother 6. Transfer to other } \\
& \text { 2. Home after Mother Hospital (Social) } \\
& \text { 3. To care of relative 7. Transfer to } \\
& \text { 4. Transfer to other ward Residential/Foster Care } \\
& \text { 5. Transfer to other 8. Dead } \\
& \text { Hospital (Medical) 9. N/K }
\end{aligned}
$$

Age (Days) / Woight

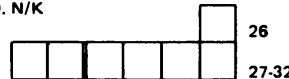

DIAGNOSIS Cardiff Code

2.

6.

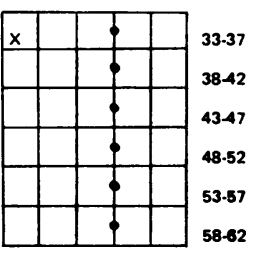

FOLLOW UP 1. None 3. Elsewhere

2. This Hospital 4. Multiple

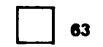

Local Option

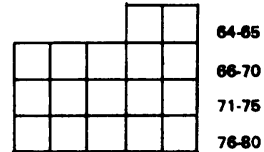

\section{MATERNAL RECORD}

Health in Prognancy Normal Abnormal

Specify

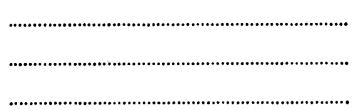

Mode of Delivery

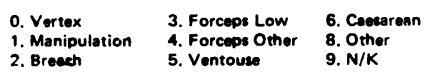

2. Breech

4. Forceps Other 8. Other
$\begin{array}{ll}\text { 5. Ventouse } & 9 . N / K\end{array}$

Fig. $2 S M R I 1$ (abbreviated baby record). 


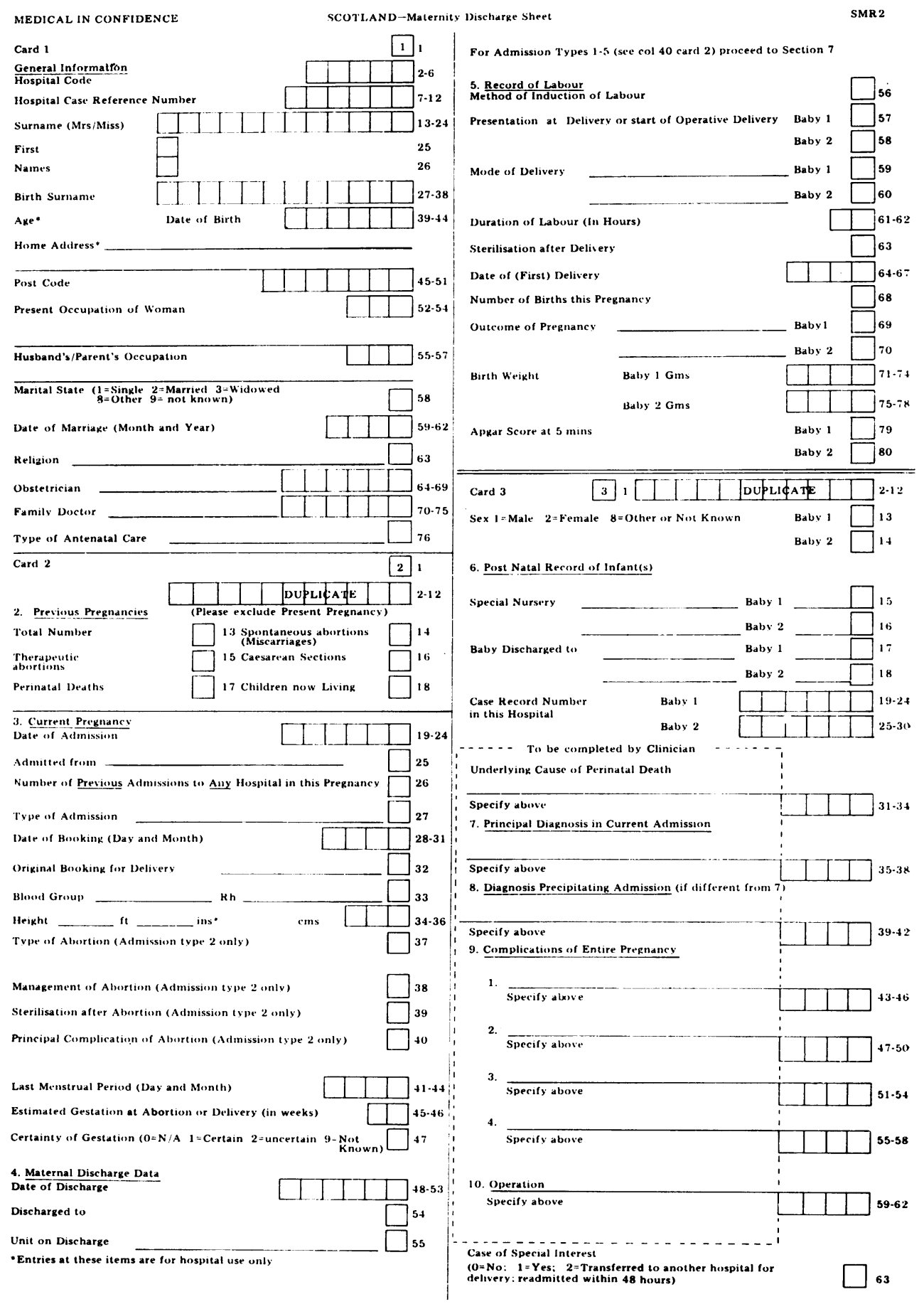

Fig. 3 SMR 2 (maternal record). 
and this can be extended to all centres using the SMR 2 record.

In any system such as this the speed with which the clinician can receive annual statistics is most important, as these are only of real value in modifying care or management of patients if readily available. The way the system now runs, with all processing and computer work being handled by the Tayside Computer Centre, the clinician can receive a print-out of the preceding year's data by March or April, the centre having received the last of the December birth records by the end of January. A delay occurred in the return of the 1974 data owing to rapid expansion of the Master Patient Register operation in Tayside (see Appendix) which necessitated distributing documents for 'punching', but the 1975 returns were available in March 1976. In future, as some centres cannot complete December records by the end of January, a second revised and final print-out will be provided about June of the following year. Ad hoc studies requested by participants have been completed in 2-3 weeks of receiving the request, even when detailed analysis of thousands of case notes has been involved.

Though the purpose of this paper is to describe the document and the system of operation and not to report actual medical data, several examples are presented to illustrate the value of the system. There are now some 21 obstetric units participating, but in order to show trends which occurred during 1973-75 the illustrations are taken from the 11 units participating since 1973. These relate to national statistics (mortality), trends in patient condition and care (resuscitation, jaundice, and breast feeding), community child care requirements (discharge to 'care'), and two illustrate computerlinked maternal and baby data.

Mortality. Table 1 gives data on hospital deaths, which do not compare accurately with perinatal or neonatal mortality data. Deaths occurring in the first week of life can easily be extracted for the preparation of the perinatal mortality rate. None the less the 'hospital deaths' show interesting trends in the rate and range. In 1974 there was a significant increase in deaths $(P<0.001)$, followed in 1975 by an equally significant fall which cannot be explained on the grounds of falling birth rate. The total number of recorded births on the program as a whole is still rising as more centres participate in the program, but the figures indicate a fall in most areas, and the inclusion of the 10 recent entrants to the scheme does not alter the significance of the fall in mortality rate.

Resuscitation. A recent leading article in the Lancet (1976) was highly critical of the low rate of intubation during neonatal resuscitation of asphyxiated babies. From the data of this nature available from the returns shown in Table 2 it seems that this criticism

Table 2 Relationship between Apgar score and method of resuscitation*

\begin{tabular}{|c|c|c|c|c|}
\hline \multirow[b]{3}{*}{ Intubation done } & \multicolumn{4}{|c|}{ Apgar score of 3 or less } \\
\hline & \multicolumn{2}{|c|}{ At 1 minute } & \multicolumn{2}{|c|}{ At 5 minutes $\dagger$} \\
\hline & $\%$ & Range \% & $\%$ & Range \% \\
\hline $\begin{array}{l}1973 \\
1974 \\
1975\end{array}$ & $\begin{array}{l}72 \cdot 8 \\
70 \cdot 2 \\
71 \cdot 8\end{array}$ & $\begin{array}{l}30-85 \\
25-78 \\
42-90\end{array}$ & $\begin{array}{l}71 \cdot 6 \\
77 \cdot 7 \\
66 \cdot 4\end{array}$ & $\begin{array}{l}50-85 \\
43-85 \\
29-82\end{array}$ \\
\hline
\end{tabular}

* Returns from hospital units participating since 1973.

†Some small sample hospitals-100\%.

is wholly justified. It is interesting that the 1974 fall in the use of intubation in babies with Apgar scores of 3 or less at one minute is associated with the increased mortality and that both showed an improvement in 1975. On the other hand, in 1975 the figure at 5 minutes suggests an actual deterioration in management, even allowing for an improved rate of intubation at one minute. There is still wide variation in the use of active measures of resuscitation which required study in respect to mortality and later morbidity on the one hand and staffing needs and labour ward policy on the other.

Jaundice. The clinical impression that neonatal hyperbilirubinaemia has increased considerably

Table 1 Deaths in hospital*

\begin{tabular}{lllllrl}
\hline & Deaths (total) & (Post mortems) & Total births & Coded NK & Deaths per 1000 live births† & Range $¥$ \\
\hline 1973 & 203 & $(101)$ & 19696 & 15 & $10 \cdot 3$ & $7 \cdot 2-16 \cdot 3$ \\
1974 & 230 & $(132)$ & 20685 & 11 & $7 \cdot 2-14 \cdot 8$ \\
1975 & 149 & $(87)$ & 18585 & 18 & $8 \cdot 0$ & $4 \cdot 12 \cdot 7$ \\
\hline
\end{tabular}

* Returns from hospital units participating since 1973.

tChanges are both significant, $\mathbf{P}=<0.001$.

tCalculated only from those hospitals with over 1000 case returns.

NK = not known. 
Table 3 Changes in incidence of neonatal jaundice*

\begin{tabular}{|c|c|c|c|c|c|c|c|c|}
\hline & \multicolumn{2}{|l|}{ Absent } & \multicolumn{2}{|l|}{ Mild } & \multicolumn{2}{|c|}{ Moderate } & \multicolumn{2}{|c|}{ Severe } \\
\hline & No. & $\%$ & No. & $\%$ & No. & $\%$ & No. & $\%$ \\
\hline $\begin{array}{l}1973 \\
1974 \\
1975\end{array}$ & $\begin{array}{r}14869 \\
15402 \\
4992\end{array}$ & $\begin{array}{l}75 \cdot 6 \\
74 \cdot 6 \\
26 \cdot 9\end{array}$ & $\begin{array}{r}4384 \\
4743 \\
12872\end{array}$ & $\begin{array}{l}22 \cdot 3 \\
22 \cdot 9 \\
69 \cdot 5\end{array}$ & $\begin{array}{l}373 \\
472 \\
529\end{array}$ & $\begin{array}{l}1 \cdot 9 \\
2 \cdot 3 \\
2 \cdot 9\end{array}$ & $\begin{array}{r}34 \\
38 \\
131\end{array}$ & $\begin{array}{l}0.2 \\
0.2 \\
0.7\end{array}$ \\
\hline
\end{tabular}

* Returns from hospitals participating since 1973.

Other increases not significant, $P<0.001$

is confirmed, the most significant rise taking place between 1974 and 1975 (Table 3). In 1975 as many as $70 \%$ (range $59-81 \%$ ) of 21030 babies had bilirubin levels between 86 and $204 \mu \mathrm{mol} / 1$ (5 and $12 \mathrm{mg} / 100 \mathrm{ml}$ ), $3 \%$ (range $1-8 \%$ ) between 205 and $340 \mu \mathrm{mol} / 1(12$ and $20 \mathrm{mg} / 100 \mathrm{ml})$, and $1 \%$ over $342 \mu \mathrm{mol} / 1(20 \mathrm{mg} / 100 \mathrm{ml})$ (Table 4). This increase and high incidence must surely raise questions about current perinatal practice.

Table 4 Incidence and degree of jaundice (1975) (21 030 babies from 16 hospital units)

\begin{tabular}{lccc}
\hline & No. & $\%$ & Range \% \\
\hline $\begin{array}{l}\text { Absent } \\
\text { Mild } \\
\text { (Bilirubin 86-204 }\end{array}$ & 5539 & 26 & $17-39$ \\
$\begin{array}{c}\mu \text { mol/1) } \\
\text { Moderate } \\
\text { (Bilirubin 205-340 }\end{array}$ & 14775 & 70 & $59-81$ \\
$\begin{array}{c}\mu \text { mol/1) } \\
\text { Severe } \\
\text { (Bilirubin }>342\end{array}$ & 578 & 3 & $1-8$ \\
\hline mol/1) & 138 & 1 & $0-1$ \\
\hline
\end{tabular}

Conversion: SI to traditional units-

Bilirubin: $1 \mu \mathrm{mol} / 1 \approx 0.059 \mathrm{mg} / 100 \mathrm{ml}$.
Infant feeding. Trends in methods of feeding, which have received much attention recently, are shown in Table 5. A significant $(P<0.001)$ increased incidence of breast feeding on discharge of about $8 \%$ is gratifying but shows that much has yet to be done if the average rate $(29.1 \%)$ is even to approach the best $(41 \%)$, which in itself is not good enough. Data on how long breast feeding is continued after discharge are, of course, not available from the SMR 11.

Community care. In addition to monitoring the number of Guthrie tests done and BCG injections given, the program can estimate the need for residential or foster care. Table 6 gives the number of children recorded as discharged to care, but the increase in 1975 is probably erroneous. All

Table 6 Discharge to residential or foster care*

\begin{tabular}{lrcl}
\hline & No. & Disposition known & $\%$ \\
\hline 1972 (trial) & 39 & 2578 & $1 \cdot 5$ \\
1973 & 245 & 19708 & $1 \cdot 2$ \\
1974 & 238 & 20690 & $1 \cdot 15$ \\
1975 & 264 & 16074 & 1.6 \\
\hline
\end{tabular}

*Returns from hospital units participating since 1973.

Table 5 Infant feeding*

\begin{tabular}{|c|c|c|c|c|c|}
\hline No. of cases recorded & Breast & Bottle & Breast and complementary & Total breast & Other + unknown \\
\hline \multicolumn{6}{|l|}{$\begin{array}{l}1972 \text { (trial) } \\
2578 \text { cases }\end{array}$} \\
\hline $\begin{array}{l}\text { No. } \\
\% \\
\text { Range \% } \\
1973 \\
19638 \text { cases }\end{array}$ & $\begin{array}{l}509 \\
19 \cdot 7 \\
11-33\end{array}$ & $\begin{array}{l}2019 \\
78 \cdot 3 \\
67-89\end{array}$ & $\begin{array}{l}39 \\
1 \cdot 5 \\
0-3\end{array}$ & $\begin{array}{l}548 \\
21 \cdot 3 \\
11-33\end{array}$ & $\begin{array}{l}17 \\
0 \cdot 7 \\
-\end{array}$ \\
\hline $\begin{array}{l}\text { No. } \\
\% \\
\text { Range \% } \\
1974 \\
22608 \text { cases }\end{array}$ & $\begin{array}{l}3867 \\
19 \cdot 7 \\
10-30\end{array}$ & $\begin{array}{l}15189 \\
77 \cdot 4 \\
67-88\end{array}$ & $\begin{array}{l}393 \\
2 \cdot 0 \\
1-4\end{array}$ & $\begin{array}{l}4260 \\
21 \cdot 7 \\
11-32\end{array}$ & $\begin{array}{l}262 \\
1 \cdot 3 \\
-\end{array}$ \\
\hline $\begin{array}{l}\text { No. } \\
\% \\
\text { Range \% } \\
1975 \\
18670 \text { cases }\end{array}$ & $\begin{array}{l}4373 \\
21 \cdot 2 \\
12-31\end{array}$ & $\begin{array}{l}15428 \\
74 \cdot 8 \\
65-85\end{array}$ & $\begin{array}{l}593 \\
2 \cdot 9 \\
1-8\end{array}$ & $\begin{array}{l}4966 \\
24 \cdot 1 \\
11-32\end{array}$ & $\begin{array}{l}229 \\
1 \cdot 1 \\
-\end{array}$ \\
\hline $\begin{array}{l}\text { No. } \\
\% \\
\text { Range \% }\end{array}$ & $\begin{array}{l}4922 \\
26 \cdot 8 \\
17-39\end{array}$ & $\begin{array}{l}12872 \\
69 \cdot 2 \\
59-80\end{array}$ & $\begin{array}{l}529 \\
2 \cdot 8 \\
1-8\end{array}$ & $\begin{array}{l}5521 \\
29 \cdot 4 \\
19-41\end{array}$ & $\begin{array}{l}217 \\
1 \cdot 2 \\
-\end{array}$ \\
\hline
\end{tabular}

* Returns from hospital units participating since 1973.

Changes between 1973-1974 and 1974-1975 significant, $P=<0.001$. 
Table 7 Correlation between method of delivery and resuscitation (Dundee hospitals, 1974)

\begin{tabular}{|c|c|c|c|c|c|}
\hline \multirow[b]{2}{*}{ Method of delivery } & \multirow[b]{2}{*}{ No. of cases } & \multirow[b]{2}{*}{ Nil } & \multicolumn{3}{|c|}{ Type of resuscitation required $(\%)$} \\
\hline & & & Drugs only & Mask + IPPV & Intubation \pm drugs \\
\hline $\begin{array}{l}\text { Spontaneous } \\
\text { Manipulative } \\
\text { Forceps (high \& mid) } \\
\text { Forceps (low) } \\
\text { Caesarean section }\end{array}$ & $\begin{array}{r}1746 \\
61 \\
362 \\
142 \\
343\end{array}$ & $\begin{array}{l}92 \\
54 \\
73 \\
78 \\
67\end{array}$ & $\begin{array}{r}2 \\
3 \\
10 \\
5 \\
5\end{array}$ & $\begin{array}{r}4 \\
15 \\
8 \\
10 \\
8\end{array}$ & $\begin{array}{r}2 \\
28 \\
9 \\
7 \\
20\end{array}$ \\
\hline
\end{tabular}

centres but two show a fall between 1974 and 1975 for this item and these two actually show a severalfold increase. This is obviously an error in understanding and illustrates the importance of the adequate training of staff and of establishing definitions in systems of this kind. Nevertheless these figures do give a rough indication of social work requirements at the time of the baby's discharge.

Maternity record linkage. Tables 7 and 8 reveal

Table 8 Correlation between method of delivery and disposition of baby (Dundee hospitals, 1974)

\begin{tabular}{llcl}
\hline & \multicolumn{2}{l}{ Disposition of baby (\%) } \\
\cline { 2 - 4 } Method of delivery & Home with mother & Home later & $\begin{array}{c}\text { Transfer for } \\
\text { further care }\end{array}$ \\
\hline Spontaneous & 85 & 5 & 10 \\
$\begin{array}{l}\text { Manipulative } \\
\text { Forceps (high \& }\end{array}$ & 58 & 19 & 19 \\
$\quad$ mid) & 72 & 10 & 16 \\
$\begin{array}{l}\text { Forceps (low) } \\
\text { Caesarean }\end{array} \quad 79$ & 71 & 14 & 4 \\
$\quad$ section & & 13 & 13 \\
\hline
\end{tabular}

interesting data in respect to the resuscitation required and disposition of the baby in relation to the method of delivery. It must be admitted that on this first year of linkage operation there is about $10 \%$ loss due to categories being entered as 'not known' in either the mother or baby record, or the failure of some records to reach the file (see below). However, both tables appear to highlight the hazards of 'manipulation' (e.g. rotation, breech extraction) and illustrate the comparative safety of timely forceps and caesarean section delivery.

\section{Discussion}

The main problem in all detailed medical documentation is ensuring that the data are complete and accurate. Added to the time required for this is secretarial time needed for transcription of data from the medical to the computer record-a potential source of error. The risk of error and the time required for completion have been reduced to a considerable extent by designing the SMR 11 in such a way that it serves as both the clinical and the computer record. The actual time taken to complete the form is no more than that taken for clinical case sheets as only circling a number or filling up a box from a printed code is required. Though the code consists of two 80-column cards the paediatric staff have only to complete some 75 entries. With the help of midwifery and/or clerical staff all maternal and identification data can be entered before or during delivery and, of course, few of the diagnostic boxes are needed for the majority of normal babies.

In the view of the working group, to examine a baby and document less than what appears on these forms is inadequate from both the clinical and data collection point of view. The form can be completed almost entirely while mother and baby are being seen in the wards by doctors and nurses, thereby improving the accuracy and eliminating the need for transcription. Because of the latter, some centres are still unable to participate, and several use the abbreviated form. Completion, of course, becomes more difficult, and perhaps for some impossible, without additional secretarial help, especially if the midwifery staff cannot initiate the record in the antenatal clinic or labour ward.

If the record is not used at the bedside then considerably more secretarial help is needed for completion after discharge. Those centres in which there was initially adequate secretarial or clerical staff for their newborn services required little extra assistance to operate this program, but where such a service did not exist previously there has been difficulty in participating, even though the extra load is small compared to most other neonatal computer programs.

An objection to bedside use is that the undercopy becomes unreadable because staff inadvertently write on top of a record, though very few of the thousands of records returned by the author's hospital have had to be rewritten because of this. Inevitably, initial problems of clinical interpretation 
occur, e.g. what constitutes a normal variant as opposed to a definite abnormality; when do sticky eyes become 'conjunctivitis', spots become a rash? Though total uniformity of definition is difficult to achieve, this is helped by adhering to the nomenclature of the Perinatal Supplement, as the wording was carefully chosen with problems of definition in mind. However, each hospital has its own criteria and when accurate comparisons are to be made the centres concerned must then agree upon diagnostic criteria.

Most rejected records are due to illegible writing rather than to errors in the choice of code numbers outside the accepted range. A humorous example was the misinterpretation of a badly written ' $X$ ' for an ' 8 ' which resulted in a large number of 'normal' babies having laceration of the upper limb! Very few rejections are due to 'punching' errors by the computer staff. Mistakes within the predetermined ranges, of course, cannot be detected by the computer. The only guarantee against these is care on the part of those completing the record since even a visual check will not easily detect slight errors in a 5- or 6-digit diagnostic code. Present junior staffing arrangements, especially those with rotating traineeships, make smooth running more difficult as it takes new staff a little time to become familiar with the system-but this is true of most hospital activities today. The inevitable teething troubles can be overcome with a little patience and persuasion. There is a gathering resistance to change, but perhaps the few illustrations presented will indicate the potential of the system and encourage the sceptic and fainthearted. It must be stressed, however, that if staff from each part of the 'mother-and-baby' care team do a little, the additional effort required of any one of these is surprisingly small for the quantity of data captured.

Despite the doubts expressed by clinicians, the review by Baldwin (1974) indicates that successful linking of records by computer has been achieved sufficiently often that confidence in this method of analysing clinical data should be growing. The need for reliable patient identification has been met by the use of the unique number method which is universally regarded as the simplest, most economical, and most reliable. It is used in the Tayside area, i.e. each individual is identified by a 10 digit number consisting of date of birth, 3 unique numbers, and a check digit. Other more complicated methods have been reported, notably the Oxford (Hubbard and Fisher, 1968) Northern Ireland (Cheeseman, 1968), and Glasgow (Richards and Nicholson, 1970) systems, and the Cardiff Births Survey, which all require more time and personnel.
The Working Group expect the form and program to be further modified at intervals to include all of Scotland. Currently between 60 and $70 \%$ of Scottish births are being documented. It is hoped that eventually the Scottish program can be coordinated with similar programs elsewhere in the UK.

Hitherto, co-operation in the field of medical records has seemed almost impossible. It appears that on this subject above all others the consultant insists on remaining an individualist, with the inevitable result that numerous incompatible systems exist throughout the land. Now that the part played by computers in medical care is established, more systems, including many related to maternal, newborn, and child care are at this moment evolving. Is it not time to gather in the wealth of experience that now exists and so avoid needless duplication of effort? Is it not time to adopt a method by which many centres can be served by one program and one computer establishment, or at least to make efforts to construct programs which are compatible and interchangeable? The potential of the SMR 11 includes revision of height, weight, and occipitofrontal head circumference centile charts for Scotland on an area or national basis, the study of trends in infant feeding and the influence of social and economic factors on morbidity and mortality, which could lead to modifications in programmes of maternity and neonatal care. It seems appropriate that at a time when so many UK activities appear to be bent on 'devolution', this one at least could retain an objective of 'incorporative evolution', so that everyone can benefit.

\section{Conclusions}

(1) To use a single combined clinical case sheet/ computer record which can form the basic document for a life medical record is a practical proposition. (2) Its use requires the willing co-operation of nurses and doctors of the whole mother-and-baby care team. (3) A minimum amount of secretarial and clerical assistance is required-thus considerably cutting staffing requirements and costs. (4) It is most unlikely, in the light of experience of other clinical computer programs, that any conventional method requiring transcription can yield annual returns in 3-4 months - the time achieved with this system. (5) This system can quickly provide the perinatal data, essential for good postnatal care, to both hospital and community personnel. (6) The data collected have already pointed to the need for change in certain aspects of patient care. The system is sufficiently flexible to yield information 
of value both to the individual hospital and to the country as a whole.

The Working Party acknowledge the invaluable assistance of Dr. M. A. Heasman and Dr. J. D. Donnelly, and the latter's successor Dr. J. A. Clarke, of the Information Services Division of the Common Services Agency, Edinburgh, for funding this project and guiding its progress; of Mr. H. Scott, Computer Manager, Tayside Health Board, and his assistants who process the SMR 11; of Mrs. J. Forbes, Secretary, and Mr. J. S. Speedie, Printing Office, Tayside Health Board, where the earlier forms were produced; of Professor 'Pop' Watkins and Mr. J. Morgan, Cardiff, Dr. Dunn, Bristol, and Miss P. Loy, Office of Population Censuses and Surveys, London, for help with the Perinatal Supplement; of Mrs. P. Easton with the statistics; of the various Records Officers throughout Scotland; and of the Midwifery and Medical Staffs for their essential part in the success of this project.

\section{References}

Baldwin, J. A. (1974). Medical record linkage. Medicine (London), 1972-74, No. 35, 2048-2054.

Cheeseman, E. A. (1968). Medical record linkage in Northern Ireland-reconnaissance and proposals with particular reference to problems of identification. Record Linkage in Medicine. Proceedings of the International Symposium, July, 1967, p. 70. Ed. by E. D. Acheson. Livingstone, Edinburgh and London.

Cockburn, F. (1974). Report by Scottish neonatal records committee. Journal of Clinical Computing, 4, 151-152.

Hubbard, M. R., and Fisher, J. E. (1968). A computer system for medical record linkage. Record Linkage in Medicine. Proceedings of the International Symposium, July, 1967, p. 157. Ed. by E. D. Acheson. Livingstone, Edinburgh and London.

Lancet (1976). (Leading article.) Born in Britain 1970, 1, 729-730.

Richards, I. D. G., and Nicholson, M. F. (1970). The Glasgow linked system of child health records. Developmental Medicine and Child Neurology, 12, 357-361.

Correspondence to Dr. C. H. M. Walker, Department of Child Health, Ninewells Hospital and Medical School, Dundee DD1 9SY.

\section{Appendix}

A Master Patient Register (MPR), to which all other computer-linked operations are related, already exists in the Tayside Area. Over 400000 people can now be identified on the computer file and to any one patient record can be added further information at any time. At birth all babies receive an MPR unique number consisting of the date of birth followed by three personal numbers and one check digit. All the mothers have a unique identification derived in the same way and the two can be linked for analysis. The addition of hospital events (SMR 1), psychiatry contact (SMR 4), and drug monitoring to the original mother (SMR 2, Fig. 3) and baby (SMR 11) data has been achieved and the computer is used in the operation of the Developmental Screening and Immunization programmes. The Community Child Health Section of the Division of Paediatrics is also linked in relation to the recording of handicap. Other operations, e.g. care of the deaf, dental care, and school medical work, are in the developmental stage and a link with services for the blind and with the Local Authority Social Work and Education Departments have yet to be investigated. Links with primary care practitioners are at an early experimental stage. Thus it can be seen that the SMR 11 plays an important part in setting the process in motion.

It must be made clear that though all patient contacts with the NHS and related services can be recorded on the MPR no actual clinical information can be obtained without access to secondary files or actual written case notes, so confidentiality is adequately safeguarded.

Note added in proof: The 1977 program now offers 112 boxes on each of the SMR 11 cards. This has permitted the enlargement of the diagnostic section for the use of the six digit items of the Perinatal Supplement of the Cardiff Diagnostic Classification. With the forthcoming revision of the ICD this sixth digit will no longer be required. The increased program has also enabled the inclusion of the coding of surgical operations and leaves ample free boxes for the collection of data required locally by the clinician or administrator. These changes also make the SMR (11) suitable for providing all the data required nationally for the Scottish Hospital Inpatient Statistics (SMR 1). A further option offered to the clinician which is proving successful is a change in the reverse side of the form. To date this has contained instructions, but it can now be produced as a Pulse, Temperature, and Weight Chart. Copies may be obtained by application to the author. 